\title{
INTELLIGENT CLASSROOM AUTOMATION SYSTEM USING PIC MICROCONTROLLER
}

\author{
Mrityunjaya Patted ${ }^{1}$, Swarada Muley ${ }^{2}$, Debamitra Panda ${ }^{3}$ \\ ${ }^{1,2,3}$ Assistant Professor, Department of Electrical Engineering, JSPM'S BSIOTR, Maharashtra, India
}

\begin{abstract}
Presently, one of the dominating problems that of we tumble is that service wastage. In our homes, schools, colleges and industries, we see that fans and lights are regularly kept ON at some future time if nothing in the dine or aspect or passage. To dodge one a status we have designed this complimentary "Classroom Automation". In our complimentary, along by all of appliances concern (i.e. fans and lights) we have integrated "Attendance Monitoring" and "Message Transmission". Modern generation class rooms are equipped by the whole of electronic devices that have more abetting software to recuperate and promote teaching methods. However, it is regularly seen that compatible class presage is stewed on seizure attendance, or the class commit face interruption guerdon to depart entries of students and disturbances such as the manual clear of groupie and light. Therefore, to recuperate these problems a both feet on the ground program is created in this thesis handout that will have no temporal intervention from teachers, students or floor attendance. Hence, the position will hasten the smooth night and day of the outstanding classes at our organization, and lessen presage loss. Thus in quickly the main desire of our free ride is to save electricity, time and maintain in functioning of classroom system smoothly.
\end{abstract}

Keywords: Automation, Robotization, Load Control, Automatic Attendance, Message Transmission

\section{INTRODUCTION}

As of late the vitality emergency has ended up one issue which the entirety world must trust. Home force utilization makes up the biggest piece of vitality utilization on the planet. Specifically, the force utilization of lights in a run of the mill home is an element which can't be disregarded. The ordinary client needs distinctive light intensities in better places. At times the light force from outside is adequate, furthermore, in this manner we don't have to turn ON any light. Be that as it may, here and there the client leaves and neglects to turn off the light. These elements cause vitality waste. In this way a few power administration of light control in a home, classrooms, workplaces and commercial ventures is fundamental keeping in mind the end goal to spare vitality[1]. Now days savvy robotization has ventured its nearness in each field all over the world. Our task is a stage towards participation and force administration of the classrooms in the schools or establishments. The utilization of minimal effort advances for exceedingly dependable applications with the assistance of recently advanced calculation makes the mechanization procedure to achieve the buyers at less expensive and solid expense. Subsequently in our task the unique mark acknowledgment framework is utilized to take the participation, power administration and remote message transmission. The classroom crew shows the situation of classroom also the oodles are controlled a well known that they ought not be repaid on in a free classroom. With upheaval of alteration, technology apparatus are becoming simpler and easier for us. Automation is reach of control systems and information technologies to lessen the desire for human work in the production of goods and services. In the term of industrialization, automation is the control beyond mechanization. Whereas mechanization has provided human operators mutually machinery to set up them with the hearty requirements of function, automation greatly decreases the man power sensory and lunatic the requirements as well. Automation plays an increasingly pertinent role in the presence economy and in daily experience. Automatic systems are considering preferred during manual system. Through this trade we have initiated to exhibit automatic control of a room as a product of which electricity is decreased to sprinkling extent.

\section{REQUIREMENT OF AUTOMATION}

Prior, we looked towards the future when we mentioned about automation/robotization, which could do anything on affectation of the controller, yet today it has transformed into a real.

Automation can supplant great measure of human working power, in addition people are more inclined to mistakes and in serious conditions the likelihood of blunder increments though, automation can work with persistence, flexibility[3].Some of the important reasons are discussed below

a) Carrying functions that are beyond human abilities of size, weight, speed, continuance, \& so forth and with exceptionally immaterial blunder.

b) Supplanting people in undertakings done in risky situations (i.e. fire, space, volcanoes, atomic offices, submerged, and so forth)

c) Supplanting human administrators in undertakings that include hard physical or dull work.

d) Economic growth. Robotization may improve in economy of endeavors, society or a vast part of humankind. For representation, when an endeavor that has placed assets into robotization, development recoups its venture, or when a state or country extends its salary because of computerization like China,Japan or Germany in the twentieth Century. 
This project is concentrating on implementation of hardware control system for various electrical and electronics devices.

\section{PROBLEM STATEMENT}

Automation involves mainly controlling and Software technology to minimize the requirement for individual ability in the generation of products and administrations. robotization significantly diminishes the necessity for human tangible and mental prerequisites also. Mechanization assumes an inexorably suited part in the survival economy and in by the day experience.

This Project can be design by using PLC anyhow the obstruction related to PLC is higher cost. Another problem is that, we can manage PLC only if the human who is handling, must be PLC literature. So to sidestep this; we are implementing Classroom Automation using microcontroller.

An ideal classroom is an environment in which teachers are able to focus solely on their lectures and the students are able to home in on the information they are being given. Unfortunately, this does not reach in our country. During class hours, time is usually wasted in multiple ways such as manually keeping record student's attendance one after another. Other disruptions besides occur throughout class time such as temperature and light variation. These problems cause hooked students to wander around the class guessing for the right switch and adjusting it to equilibrate the environment back to useful conditions. This causes disturbances for both teachers and other students, accordingly to wipe out these irritations an smart classroom system is created that allows the classroom to commence more efficient, and rescind any human assistance.

\section{PROPOSED SYSTEM}

Figure 1 describes the block diagram of proposed system. It mainly includes Microcontroller, Relays and Sensors.

\subsection{Light Dependent Resistor}

A Light Dependent Resistor (LDR) or a photo resistor is a gadget whose resistivity is an element of the occurrence electromagnetic radiation. Consequently, they are light delicate gadgets. They are likewise called as photo conductors, photo conductive cells or just photocells. They are comprised of semiconductor materials having high resistance.

LDRs or Light Dependent Resistors are extremely helpful particularly in light/dim sensor circuits. Ordinarily the resistance of a LDR is high, once in a while as high as $1000000 \mathrm{ohms}$, yet when they are lit up with light resistance drops drastically. At the point when the light level is low the resistance of the LDR is high. This keeps current from streaming to the base of the transistors. Thus the LED does not light. In any case, when light sparkles onto the LDR its resistance falls and current streams into the base of the primary transistor and after that the second transistor. The LED shines. The preset resistor can be turned up or down to increment or diminishing resistance; along these lines it can make the circuit pretty much delicate. The figure 2 demonstrates the working hardware of LDR.

\subsection{Lm35 (Temperature Sensor)}

The LM35 is an IC senses the temperature where the output voltage is always proportional to the temperature input in ${ }^{\circ} \mathrm{C}$. The circuit of the LM35 sensor that is used to detect the temperature is sealed. While temperature can be measured using a thermistor, an LM35 is used instead because of its ability to measure temperature with a greater degree of accuracy.

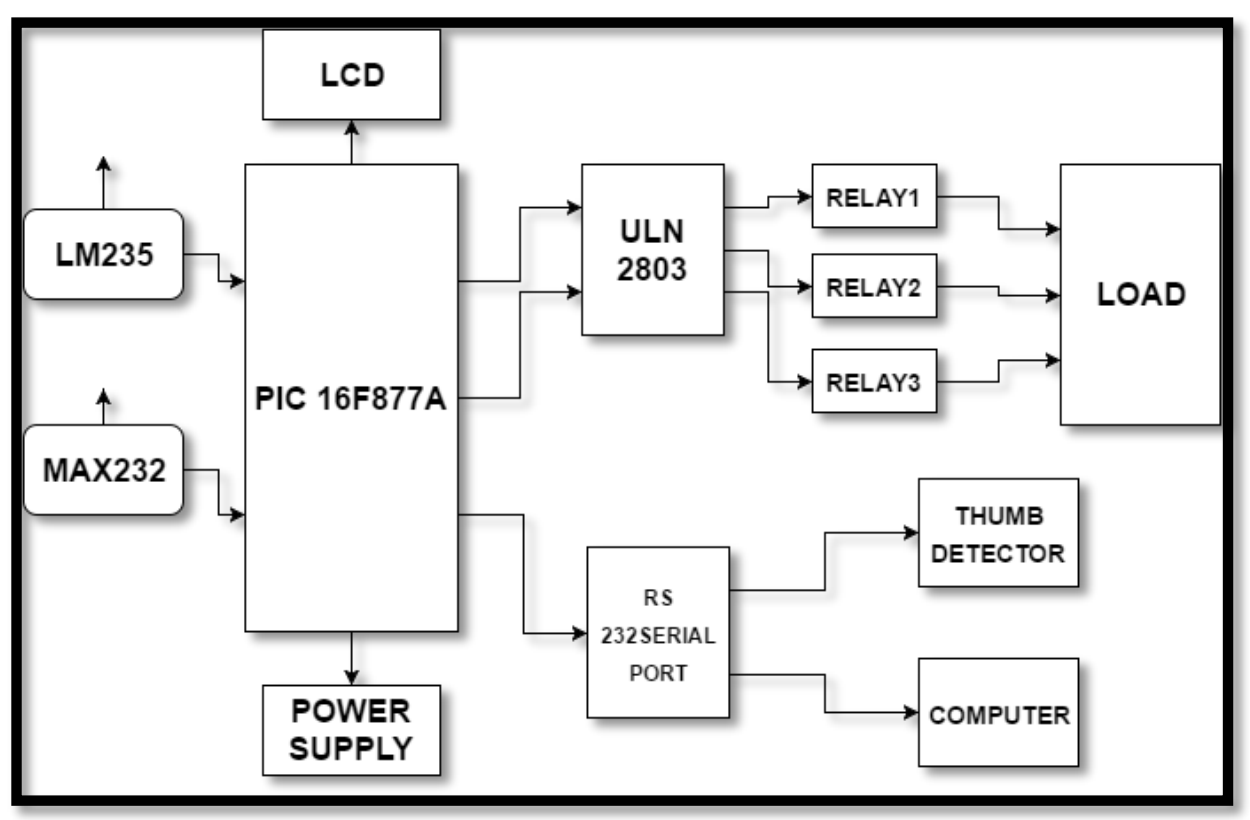

Figure1. Proposed System Block Diagram 


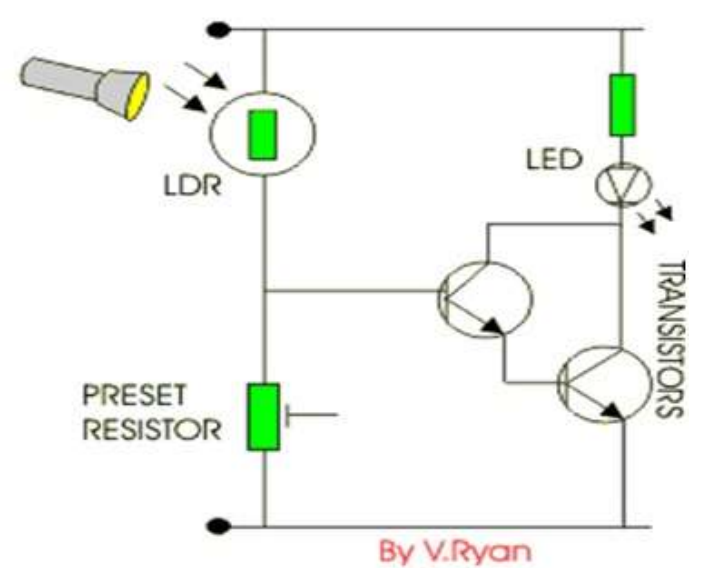

Figure 2. Working of LDR

It is a low self-heating device and does not exceed $0.1 \mathrm{C}$ temperature rise or fall when operating. The operating temperature of the $\mathrm{LM} 35$ ranges from $-55^{\circ} \mathrm{C}$ to $150^{\circ} \mathrm{C}$. One feature of the LM35 that must be noted is that its output voltage changes by $10 \mathrm{mV}$ with every ${ }^{0} \mathrm{C}$ rise and fall. Its scale factor is given as $0.01 \mathrm{~V}$ per ${ }^{0} \mathrm{C}$. For example, if the temperature of the surrounding environment was $23 \mathrm{C}$, the output voltage is expected to be $23 \mathrm{mV}$, but due to this variation from the LM35 the voltage detected could be anywhere from $13 \mathrm{mV}$ to $33 \mathrm{mV}$. Therefore the variation of the output voltage must be noted when the system is being set up. The figure 3 shown below is the LM35 used in the project.

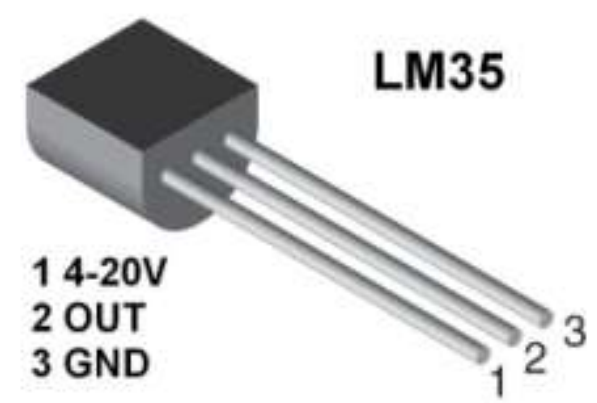

Figure 3. LM 35 Pin Details

Pin 1 is the VCC i.e. supply voltage which is $5 \mathrm{~V}$. Pin 2 is the Output Voltage where the Voltage would be $6 \mathrm{~V}$, and Pin 3 is ground pin for the LM35.

\subsection{Relay}

Working of relay as appeared in figure 4, when the force is supplied to relay, the current begin moving through the control coil subsequently electromagnetic begins empowering. Hear focuses A,B,C are utilized as controling points. At the point when power supply is given because of electromagnetic impact, $\mathrm{B}$ and $\mathrm{C}$ are associated accordingly shuts the contacts bringing about a short circuit for supply to the load. Already if relay was deenergized because of closed contacts, then the movement of contact would be inverse and make a circuit open. At the point when supply is made off, point $\mathrm{A}$ and $\mathrm{C}$ are associated. The force is essentially given by gravity and spring.

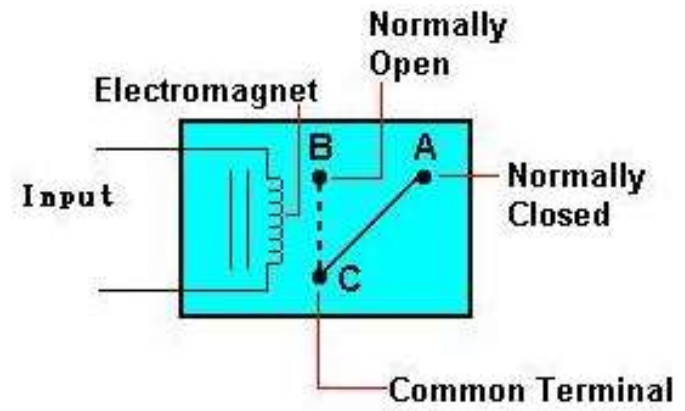

Figure 4. Working of Relay

\subsection{Pic Microcontroller}

A family of microcontrollers also possesses peripheral interface controllers universally called as PIC which is a Microchip technology. PIC 16F877A microcontrollers have alluring characteristics or features and they are reasonable for an extensive variety of uses. PIC microcontrollers are RISC processors and utilize Harvard architecture. It is a recent technology and left the necessity to accelerate the processor. The Harvard architecture makes utilization of discrete coding and software technologies. PIC 16F877A comes under the group of CMOS 8-bit Flash controllers. Aside from the flash program memory it also consists of EEPROM.

\subsection{PIN Configuration of PIC 16F877A}

As shown in the figure 5, PIC 16F877A is a 40-pin controller. There are pins corresponding to five I/O ports, namely, PORT A, PORT B, PORT C, PORT D and PORT E. Analog inputs to AD converter are AN0 to AN7; and are the alternate functions of PORT A and PORT E. Two pins are for oscillator connections, namely, OSC1 and OSC2. Supply and reference ground pins VDD and VSS, respectively, are in duplicate. Further, functions associated with the parallel slave port and serial communications are the alternate functions of PORT C and PORT D. RB0/INT is the external interrupt pin.

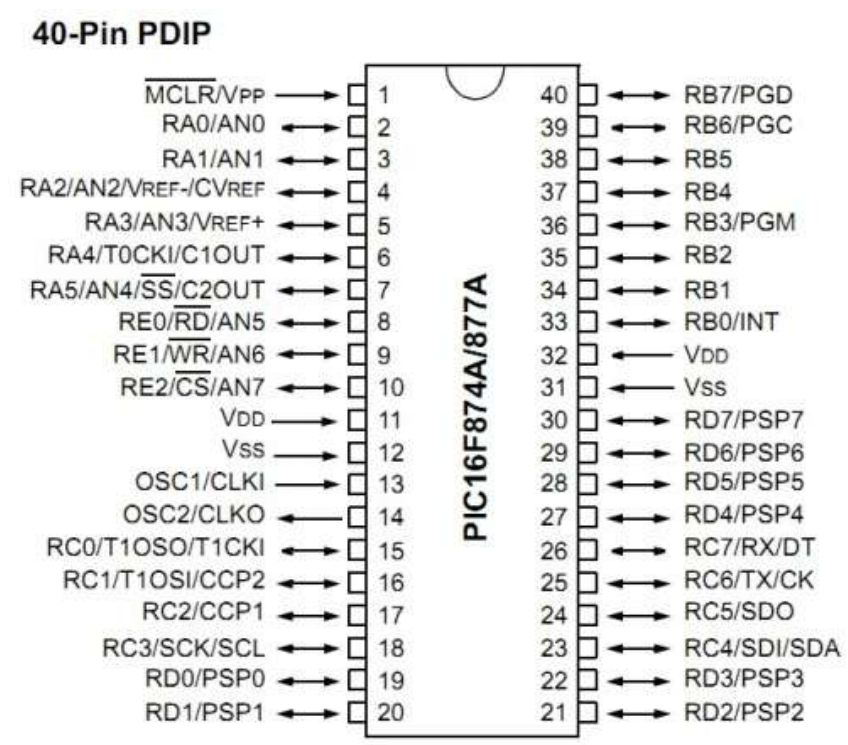

Figure 5. Pin Details of PIC 16F877A 


\subsection{Programming In PIC 16F877A}

The programming has been done by using hitech $\mathrm{C}$ compiler. The program code is done in $\mathrm{C}$ and saved in a (.C) file. The header file (pic1687x.h) and library file (p16F87.lib) and linker file (16F87.lkr) are included. The source file is a (.C) file and the workspace is stored as a (.hex) file. The source code is built using pic-kit and the source code is loaded in the PIC for generating signals to the relays.

\subsection{Power Supply Circuit for PIC 16F877A}

As shown in figure 6, LM7805 is a series regulator. C2, C4 are bypass capacitors $\mathrm{C} 1, \mathrm{C} 3$ are decoupling capacitors. During the absence of DC supply $\mathrm{C} 1$ charges and balance the input voltage needed for series regulator. The $+5 \mathrm{~V}$ regulated DC power supply is derived from a regulator IC 7805 whose input voltage is unregulated DC supply of around $12 \mathrm{~V} \mathrm{DC}$ applied to the input pin of the regulator IC after filtering AC component through capacitors. The regulator IC keeps the line and load regulation within $1 \%$ of throughout voltage and once again the capacitors are used to reduce the ac components on voltage. Capacitors $\mathrm{C} 2$ and $\mathrm{C} 4$ are used for high frequency noise rejection. Capacitor C3 improves the load regulation.

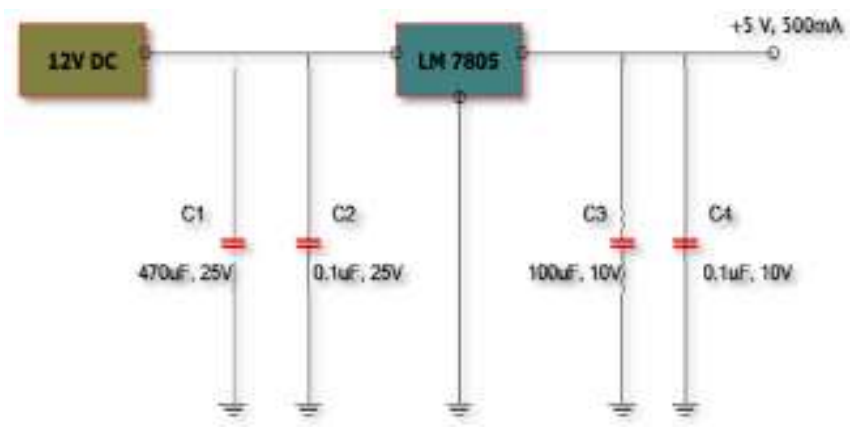

Figure 6. Power Supply Circuit for PIC 16F877A

\section{CIRCUIT DIAGRAM AND WORKING}

Figure.7 describes the circuit connection of whole model of classroom automation system with three applications i.e. i) automatic attendance ii) load control iii) Message transmission.

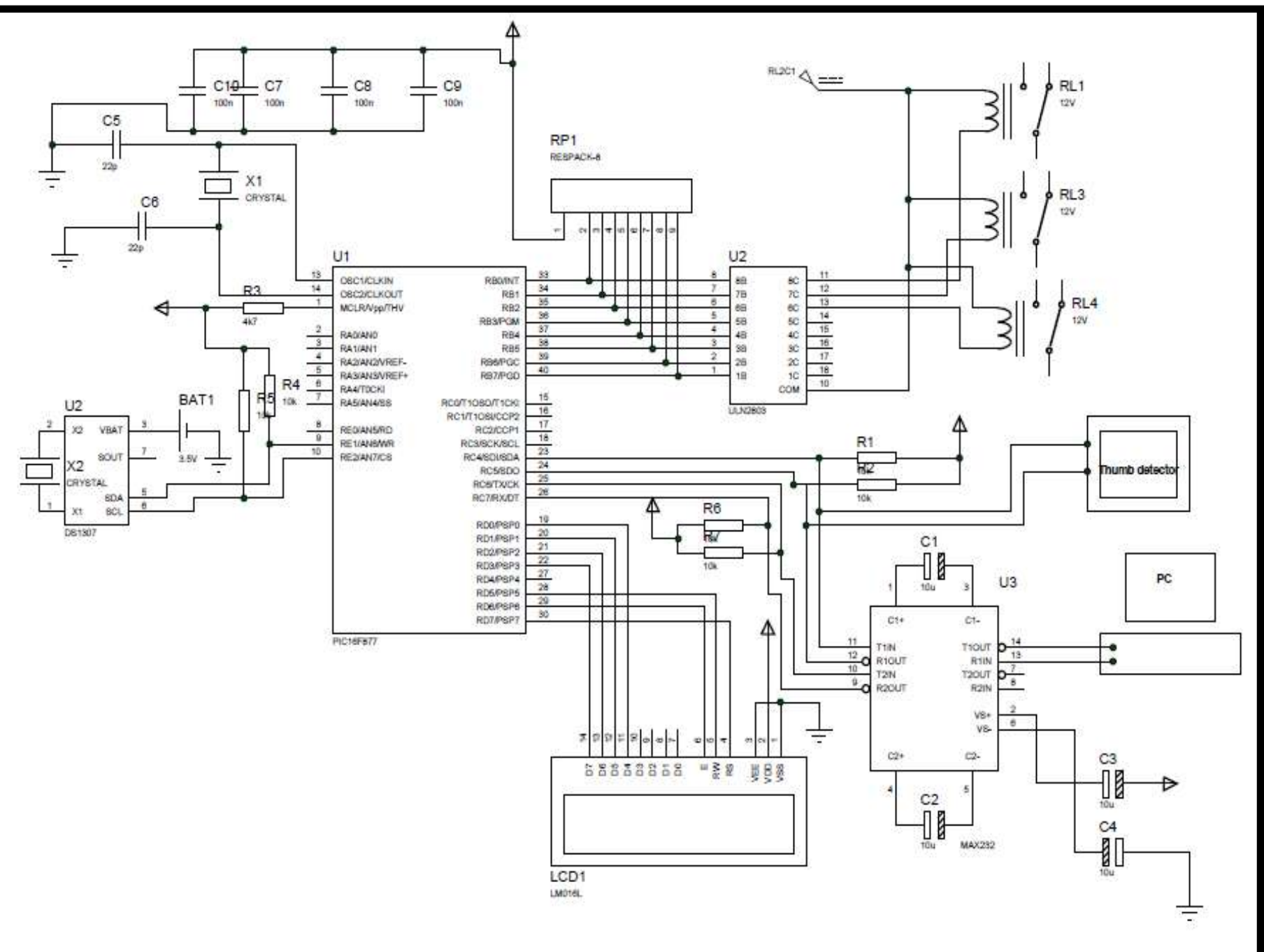

Figure 7. Circuit Diagram of Proposed System 
Automatic attendance system: The first part of the system is to automatically take attendance from thumb prints by thumb detector. Here in this project we have initiated to automate a classroom attendance procedure by using a fingerprint recognition module. Fingerprint recognitionsystem can be utilized for both check and ID. In confirmation, the framework verifies a given finger impression to the "already provided" unique finger impression of a particular client to appear in the event that they are from the same finger (1:1 match). In recognizable proof, the framework compares an information of individual finger mark with the prints of all enlisted clients in the database to display if the individual is prior known under a copy or false personality (1:N match).

Load control: The second objective is to automatically control the fan and lights. The subject is to fabricate several sensors overall the classroom and give a planned feedback to the response these sensors receive. An example would be having temperature sensors during the class room that would examine the temperature and carry out to any change by altering the fan speed. For light control, there will be proximity sensors that would detect student's presence and allows the lights to run on if students are nearby.

Message Transmission: The third important part is to convey the message on the LCD screen/Display located in the classrooms. Any urgent messages related to students or staff will be displayed immediately. The notice has been transmitted through monitor of Head of the department or authority.

\section{EXPERIMENTAL SET UP}

The hardware arrangement of whole project with already mentioned three applications is shown in the figure. 8 which includes control unit, supply unit, pc interface for message transmission. Red and Green LEDs are used to indicate the attendance entry and matching of fingerprint. If the finger print of student is matched, LED glows to Green which indicates the presence of student and data will be stored accordingly in the computer connected to the microcontroller with serial bus. Fan and Bulb are connected with temperature sensors controlled by microcontroller. The detailed working of the setup has been explained already in the previous section.

\section{RESULTS}

The results are differentiated in three main applications as shown in figure.9a, figure $9 \mathrm{~b}$ and figure $9 \mathrm{c}$ respectively.

Automatic Attendance: When the finger print of the student is matched LCD Displays the entry and finger id will be stored.

Load Control: If the intensity of the light is below set point then the bulb glows and if the room temperature is above $30^{\circ} \mathrm{C}$ then fan starts running.

Message Transmission: The required message to be displayed on LCD display located in class room will be typed in VB.NET software and processed.

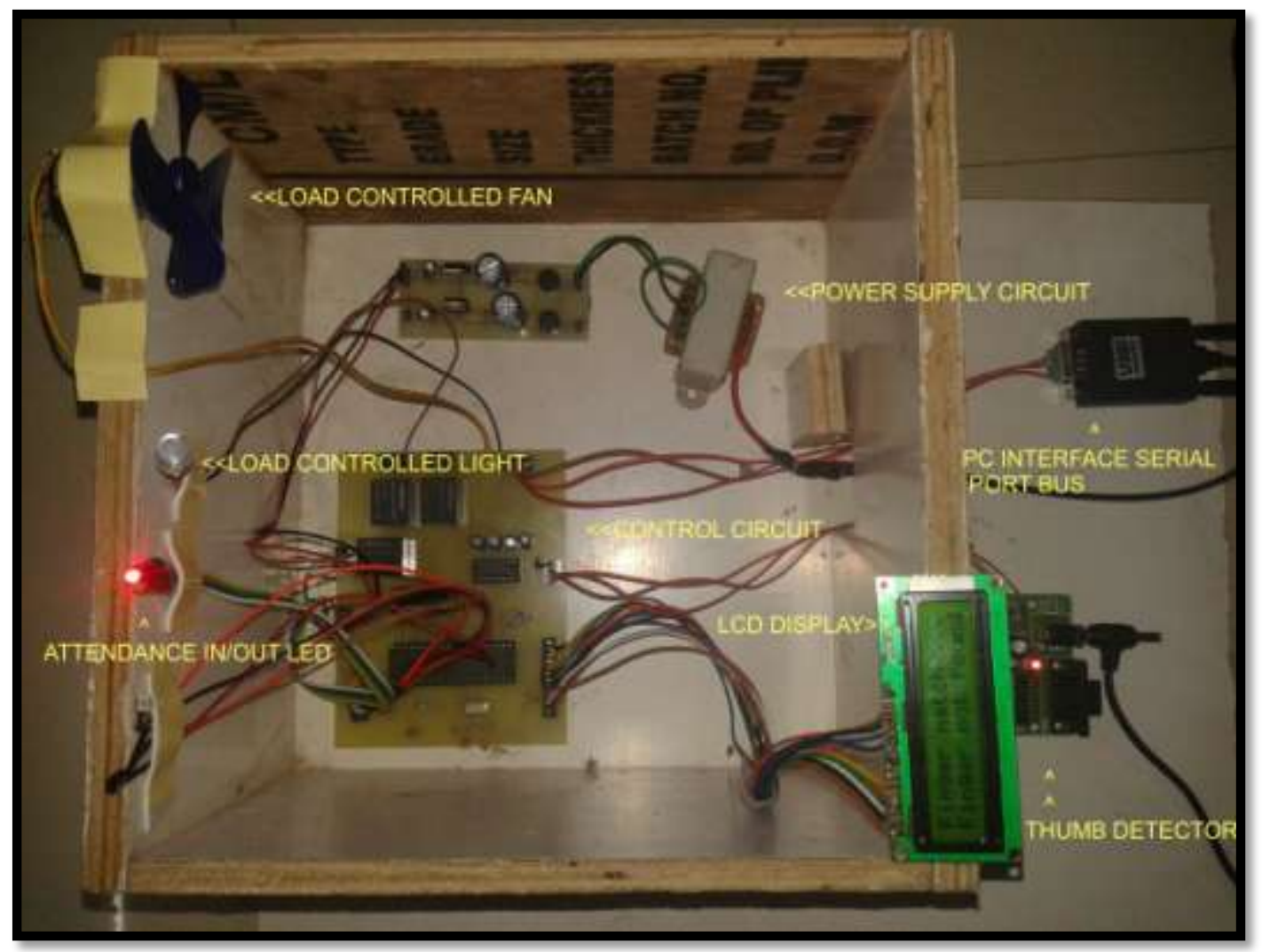

Figure 8. Hardware setup of Entire Project 


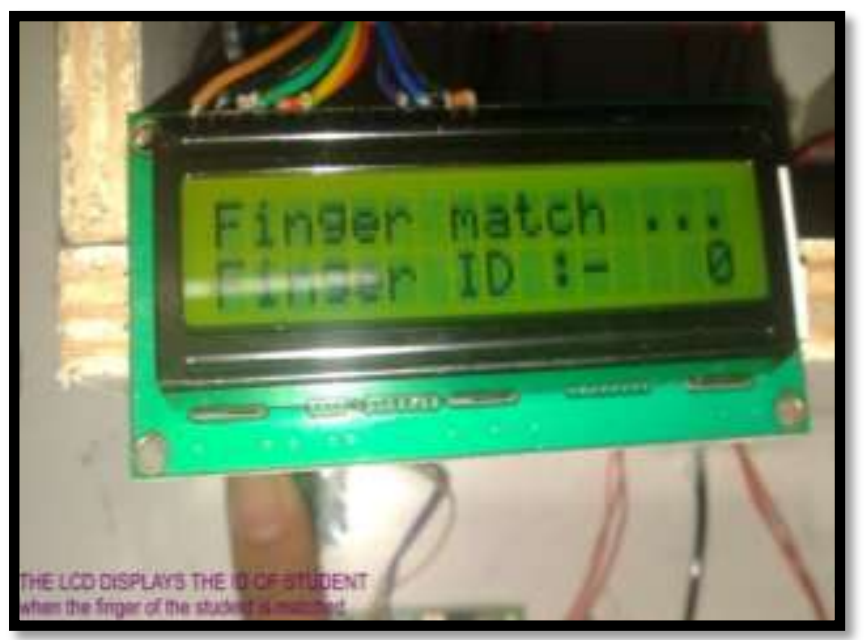

Figure 9a. Automatic Attendance using Thumb Detector

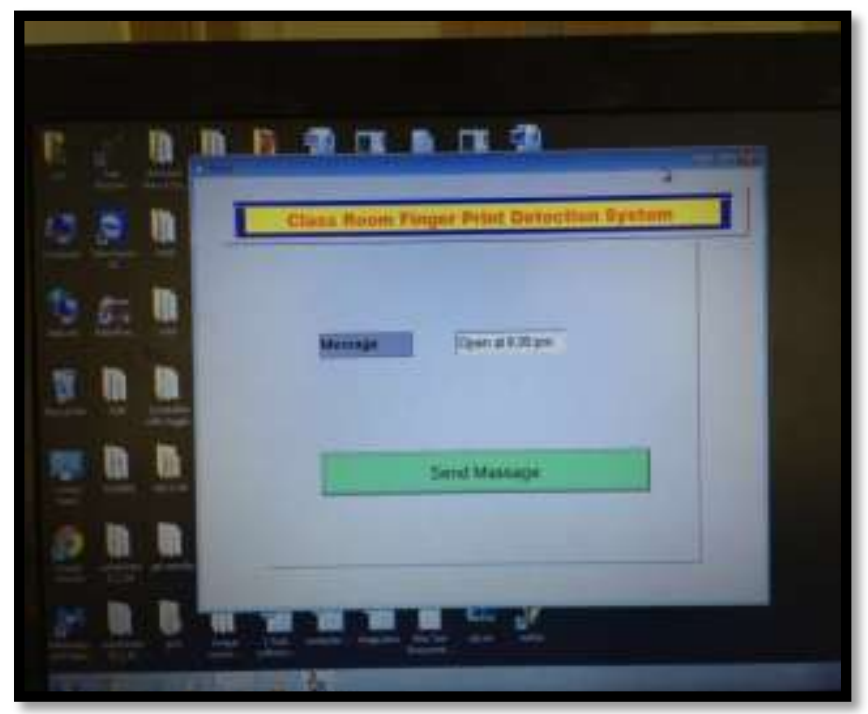

Figure 9b. Message Transmission using VB.NET Through PC

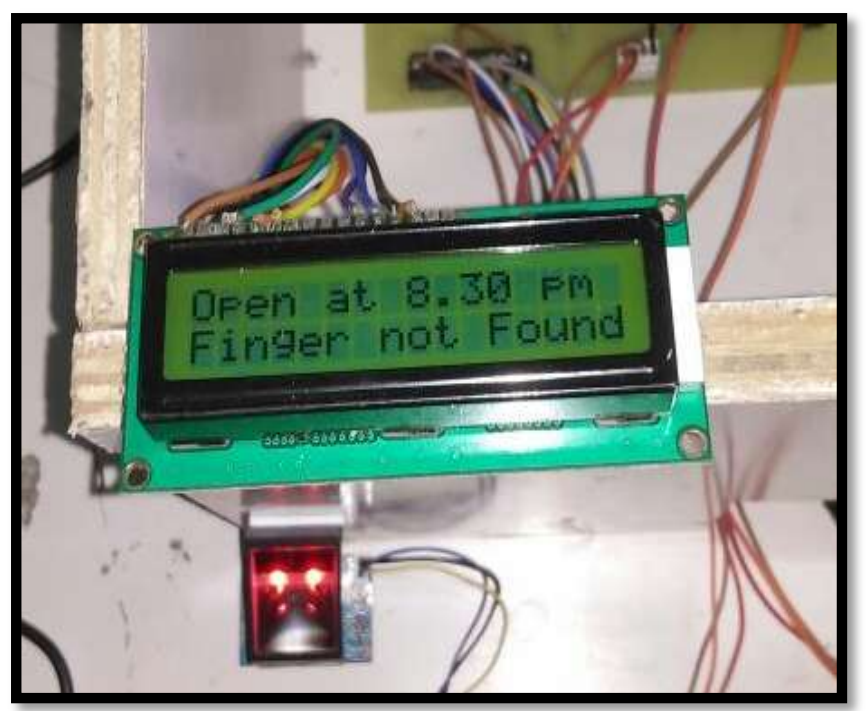

Figure 9c. Message is Displaying at LCD

\section{CONCLUSION}

The hypothesis and idea of the intelligent classroom automation model depends on the control framework. In electrical outline, the functions and characteristics of the electrical segments are needed to decide the model prerequisite. The framework lessened numerous issues, for example, bypassing the chances of malpractices in the attendance entry record, helps to maintain the data of students entry to the lectures very accurately or in a proper manner, the encryption system includes more security so that there will be no mysterious unique mark which can mess around with the recorded information and which can save time in taking attendance and also the message transmission which can reduce the interruption of class, hence the system will facilitate the smooth running of the scheduled classes at our university, and minimize time loss. This project has presented design and development of classroom automation using microcontroller. We can save the electricity with our proposed work, where we have focused on energy saving with load control in classrooms and time management with the help of attendance monitoring which is based on fingerprint identification.

\section{ACKNOWLEDGEMENT}

We gratefully acknowledge my beloved students Ms. Poorva Shinde, Ms. Pooja.W and Ms. Pooja shinde for their great help in the completion of the project.

We would like to express our sincere gratitude to Dr. N.N. Ghuge HOD Electrical Engineering Department, BSIOTR, PUNE for his support and cooperation.

We also thank all our colleagues and friends for their motivation and immense support.

\section{REFERENCES}

[1]. Kyong Nam Ha, Kyong Chang Lee, Suk Lee "Developement of PIR sensor based indoor location detection system for smart home", in proceedings of the SICE-ICASE. International Joint Conference, pp.2162\{2167,oct.18-21,2006.

[2]. Devendra Kumar Yadav, Sumit Singh, Prof. Shashank Pujari, Pragyan Mishra UG Student, Dept. of ECE, Sambalpur University Institute of Information Technology, "Fingerprint based Attendance system using microcontroller and labview.'International Journal of Advanced Research in Electrical, Electronics and Instrumentation Engineering (An ISO 3297: 2007 Certified Organization)Vol. 4, Issue 6, June 2015

[3]. Inderpreet Kaur (Asstt. Prof.) "Microcontroller Based Home Automation System With Security" (IJACSA) International Journal of Advanced Computer Science and Applications, Vol. 1, No. 6, December 2010.

[4]. http://www.pitt.edu/ sorc/robotics/, Lukas Hoffmann, PIC 16F877A Tutorials.

[5]. Automatic Room Light Controller with bidirectional visitor counter | VOL-I Issue-4| ISSN: 2395-4841 .http://www.ijictrd.net/papers/IJICTRDV1I4005.pdf

[6]. www.slideshare.net 
[7]. https://www.pantechsolutions.net/project its/interfacing-lcd-with-pic16f877a-friendly

[8]. http://www.explainthatstuff.com/fingerprintscanners.ht $\mathrm{ml}$

[9]. www.ti.com/lit/ds/symlink/lm35

\section{BIOGRAPHIES}

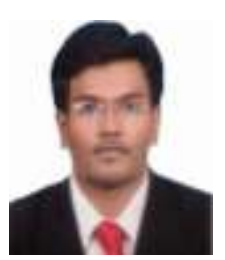

Mrityunjaya Patted is presently working as an Assistant professor in JSPM'S BSIOTR, Wagholi, Pune. He is having teaching experience of 2 years and 1 year of industrial experience with Master Degree specialization in Power electronics.

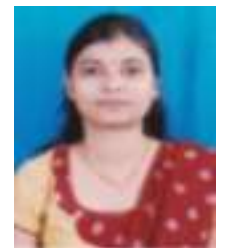

Swarada Muley is presently working as an Assistant professor in JSPM'S BSIOTR, Wagholi, Pune. She is having 4 years of teaching experience with master degree specialization in Control System.

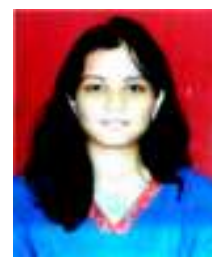

Debamitra Panda is working as an Assistant Professor in JSPM's BSIOTR, Wagholi, Pune. She is having 8 years of teaching experience with master degree in Power Electronics and drives. She is also an author for Technical Publication's Restructuring and Deregulation book. 